\title{
Patiromer Lowers Serum Potassium When Taken without Food: Comparison to Dosing with Food from an Open-Label, Randomized, Parallel Group Hyperkalemia Study
}

\author{
Pablo E. Pergola ${ }^{a}$ David M. Spiegel ${ }^{b}$ Suzette Warren ${ }^{b}$ Jinwei Yuan ${ }^{b}$ \\ Matthew R. Weir ${ }^{\mathrm{C}}$ \\ a Renal Associates, P.A., San Antonio, TX, ${ }^{b}$ Relypsa, Inc., a Vifor Pharma Group Company, Redwood City, CA, and \\ 'University of Maryland, Baltimore, MD, USA
}

\section{Keywords}

Hyperkalemia $\cdot$ Patiromer · Potassium

\begin{abstract}
Background: Patiromer is a sodium-free, nonabsorbed, potassium binder approved for treatment of hyperkalemia. This open-label study compares the efficacy and safety of patiromer administered without food versus with food. Methods: Adults with hyperkalemia (potassium $\geq 5.0 \mathrm{mEq} / \mathrm{L}$ ) were randomized (1:1) to receive patiromer once daily without food or with food for 4 weeks. The dosage was adjusted (maximum: $25.2 \mathrm{~g} /$ day) using a prespecified titration schedule to achieve and maintain potassium within a target range (3.8-5.0 mEq/L). The primary efficacy endpoint was the proportion of patients with serum potassium in the target range at either week 3 or week 4. Safety was assessed by adverse events (AEs) and laboratory testing. Results: Efficacy was evaluated in 112 patients; 65.2\% were $\geq 65$ years of age, $75.9 \%$ had chronic kidney disease, and $82.1 \%$ had diabetes. Baseline mean serum potassium was similar in the withoutfood (5.44 mEq/L) and with-food (5.34 mEq/L) groups. The primary endpoint was achieved by $87.3 \%$ (95\% Cl 75.5-94.7) and $82.5 \%$ (95\% Cl 70.1-91.3) of patients in the with-food and
\end{abstract}

\section{KARGER}

E-Mail karger@karger.com www.karger.com/ajn
This is an Open Access article licensed under the terms of the Creative Commons Attribution-NonCommercial 3.0 Unported license (CC BY-NC) (www.karger.com/OA-license), applicable to the online version of the article only. Distribution permitted for non-commercial purposes only. without-food groups, respectively; least squares mean changes in serum potassium from baseline to week 4 were -0.65 and $-0.62 \mathrm{mEq} / \mathrm{L}$, respectively $(p<0.0001)$. The most common AEs were diarrhea and constipation. Serum $\mathrm{K}^{+}$remained $\geq 3.5 \mathrm{mEq} / \mathrm{L}$ in all patients; 5 patients developed serum magnesium $<1.4 \mathrm{mg} / \mathrm{dL}$, including 4 whose baseline magnesium was below the lower limit of normal. Conclusion: Patiromer is equally effective and well tolerated when taken without food or with food, thereby offering the potential for dosing flexibility.

(c) 2017 The Author(s)

Published by S. Karger AG, Basel

\section{Introduction}

Hyperkalemia is a common life-threatening condition that often complicates the management of heart failure (HF) and chronic kidney disease (CKD) $[1,2]$. This issue is increasingly evident with the greater use of renin-angiotensin-aldosterone system (RAAS) inhibitors, which have been shown to improve survival in patients with $\mathrm{HF}$ [3-5] and decrease proteinuria and the slow progression of CKD [6-8]. Moreover, optimal RAAS inhibitor dosing has been associated with enhanced survival and lower 
medical costs compared with suboptimal dosing in observational studies [9-11]. Despite their life-prolonging and disease-modifying effects, RAAS inhibitor use is often limited to less than maximal doses or discontinued due to the development of hyperkalemia [12-15].

Patiromer (Veltassa ${ }^{\circledR}$; Relypsa, Inc., a Vifor Pharma Group Company, Redwood City, CA, USA) is a sodiumfree, nonabsorbed, potassium-binding polymer approved for the treatment of hyperkalemia in the United States; it recently was also approved in the European Union [16, 17]. In the OPAL-HK trial, patiromer reduced serum potassium levels in CKD patients receiving RAAS inhibitors who developed mild or moderate-to-severe hyperkalemia [18]. In a subsequent randomized withdrawal phase among patients with normalized serum potassium, patiromer was significantly more effective than placebo in preventing recurrence of hyperkalemia $(p<0.001)$; consequently, $94 \%$ of patiromer-treated patients remained on RAAS inhibitor therapy compared to $44 \%$ of patients in the placebo group [18]. Comparable results were seen in a prespecified analysis of hyperkalemic HF patients participating in OPAL-HK [19]. In the AMETHYST-DN trial, the efficacy and safety of patiromer in maintaining serum potassium were observed over 52 weeks in outpatients with diabetes mellitus, CKD, and hypertension who had hyperkalemia on RAAS inhibitor therapy [20]. Patients in the aforementioned clinical studies received patiromer with food in a twice-daily (BID) dosing regimen $[18,20]$. Here, we report results from the TOURMALINE study, which was designed to compare the efficacy and safety of patiromer given once daily (QD) without food versus with food for the treatment of hyperkalemia.

\section{Methods}

\section{Study Oversight}

The protocol was approved by a central institutional review board. All patients provided written informed consent; the study was conducted in accordance with the International Conference on Harmonization Good Clinical Practice guidelines.

\section{Study Population}

Adult patients ( $\geq 18$ years old) with hyperkalemia (defined as 2 local potassium values $>5.0 \mathrm{mEq} / \mathrm{L}$; each obtained from separate venipunctures in different arms, when possible) were eligible. Patients receiving RAAS inhibitors, beta blockers, or diuretics were required to be on stable doses for at least 14 days prior to screening, and any concomitant medications taken consistently had to be given QD or BID. Patients could have clinically stable CKD, HF, diabetes mellitus (type 1 or 2), and/or hypertension, but none of these disorders was a requirement for study entry.
Key exclusion criteria included major organ transplantation, dialysis or expected need for dialysis, cardiovascular event or intervention within 3 months before screening, hemodynamically unstable arrhythmia, hospitalization for HF within the previous 3 months, and poorly controlled diabetes mellitus or blood pressure. Patients who received treatment with calcium or potassium supplementation or sodium or calcium polystyrene sulfonate within 7 days before screening were also excluded.

\section{Study Design and Procedure}

This was an open-label study conducted at 29 sites in the United States in which eligible patients were randomized in a 1:1 ratio to receive patiromer QD either without food or with food (Fig. 1). Patients who were hyperkalemic at the screening visit - defined as serum potassium levels $>5.0 \mathrm{mEq} / \mathrm{L}$ in both of the screening samples measured by point of care device (iSTAT; Abbott Point-ofCare, Princeton, NJ, USA) and who met all other eligibility criteria, fasted overnight (water was permitted) and returned the next day for the baseline visit (day 1). The morning of the baseline visit (day 1), patients were randomized and blood samples were obtained immediately before the initial $8.4 \mathrm{~g}$ dose of patiromer (baseline/hour 0 ). Patients began their randomly assigned patiromer dosing on day 2. Patients randomized to the with-food group were instructed to take patiromer from initiation to within $30 \mathrm{~min}$ after finishing a meal or other food; patients randomized to the without-food group were instructed to take patiromer at least $1 \mathrm{~h}$ before or 2 or more hours after eating a meal or other food. Patients were instructed to take concomitant oral medications at least $6 \mathrm{~h}$ before the first dose of patiromer (per the label instructions at the time). Thereafter, patients were instructed to take their patiromer dose around (without-food group) or with (with-food group) a specific meal, which was chosen by each patient so that the patiromer dose was taken separate from their daily or twice daily concomitant oral medications. Patients recorded the time when patiromer was taken and the time when food was eaten in a daily diary for the duration of the study. Patients were allowed to continue their usual diets without study-prescribed dietary counseling.

Following day 1, randomized patients attended scheduled study visits on day 3 , and then weekly at $1,2,3$, and 4 weeks after starting patiromer treatment. For safety, patients were followed for 2 weeks after the last dose of patiromer (2 visits).

Potassium levels were measured by both local and central laboratories at each scheduled visit. Central laboratory measurements were used for assessments of efficacy and safety. The local potassium measurement was obtained by iSTAT Point-of-Care device. Local measurements were used for study entry criteria, dose titration, and safety assessments at study sites. During the study, patiromer daily doses could be increased or decreased by $8.4 \mathrm{~g} /$ day to a maximum of $25.2 \mathrm{~g} /$ day according to a prespecified titration schedule to achieve and maintain potassium levels within the target range of 3.8-5.0 mEq/L (Table 1).

\section{Study Endpoints}

The primary efficacy endpoint was the proportion of patients with serum potassium in the target range $(3.8-5.0 \mathrm{mEq} / \mathrm{L})$ at either week 3 or 4 . The secondary efficacy endpoint was the treatment group difference in serum potassium change from baseline to week 4 . Safety variables consisted of all adverse events (AEs); clinical laboratory test results (including serum potassium, calcium, and magnesium); vital signs (including blood pressure); and early withdrawal data. 


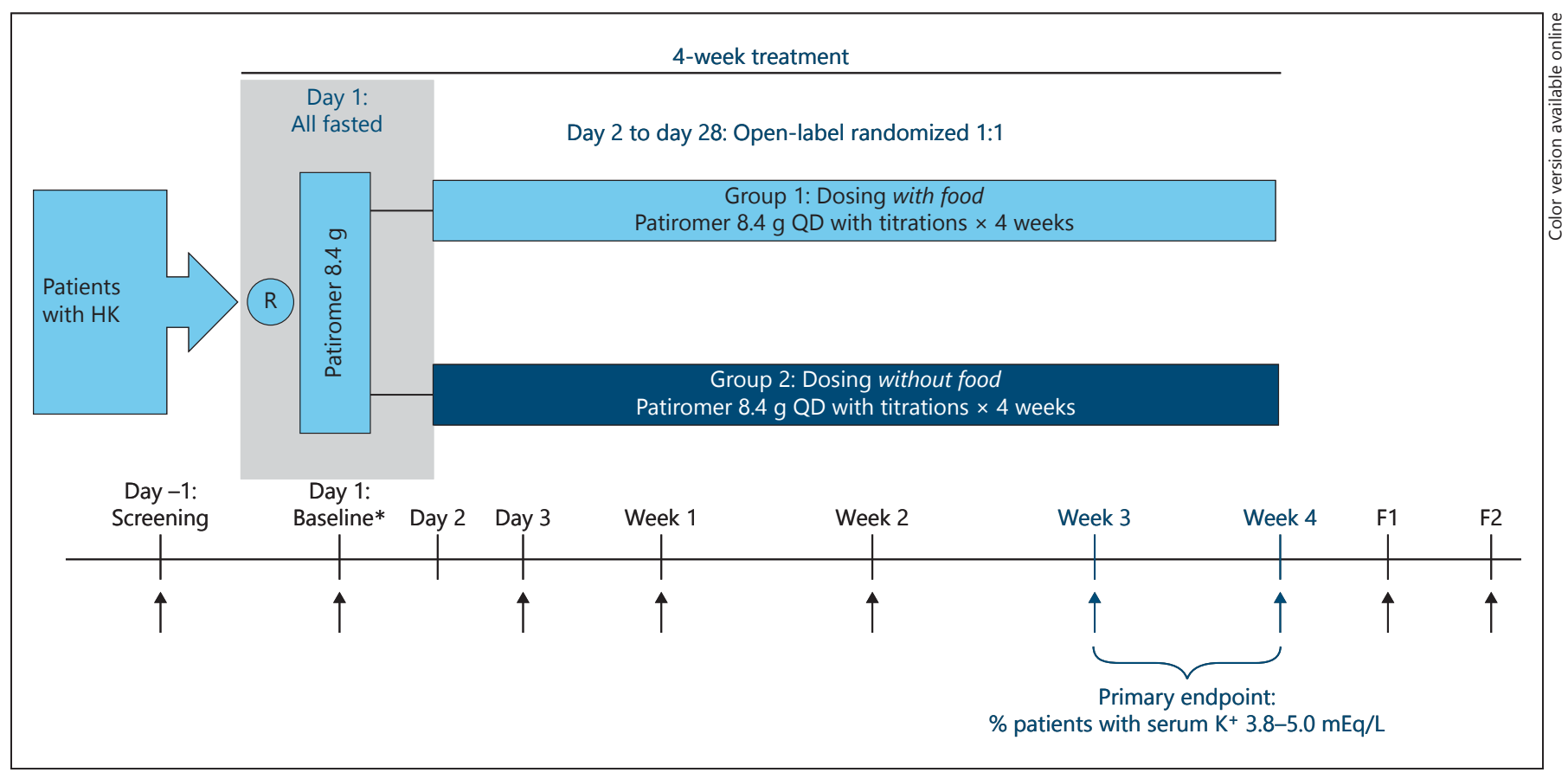

Fig. 1. Study schema for without-food and with-food dosing. $\uparrow$, scheduled blood draw; B, baseline; F1, follow-up; F2, follow-up visit 2; HK, hyperkalemia; QD, once daily; R, randomized; * At the baseline visit (day 1), patients remained fasted from the evening before and blood samples were obtained immediately prior to the

\section{Statistical Analysis}

The efficacy and safety populations included all patients who were randomized and had taken at least one dose of patiromer. For the primary efficacy analysis, the proportion of responders (patients with serum potassium in the target range $[3.8-5.0 \mathrm{mEq} / \mathrm{L}]$ at either week 3 or 4) and its 95\% CI were obtained using the Exact (ClopperPearson) method. No statistically significant difference between treatment groups was to be concluded if the CIs overlapped. The proportion of responders in prespecified subgroups by baseline serum potassium $(<5.5$ or $\geq 5.5 \mathrm{mEq} / \mathrm{L}$ ), race (white vs all other), estimated glomerular filtration rate (eGFR; $\geq 30$ or $<30 \mathrm{~mL} / \mathrm{min} / 1.73 \mathrm{~m}^{2}$ ), and diabetes mellitus (yes vs. no) was analyzed similarly.

The secondary efficacy analysis of mean change in serum potassium from baseline to week 4 used a parallel-lines analysis of covariance model to estimate the difference between treatment groups. The model included treatment group, baseline serum potassium as a continuous covariate, and race and history of diabetes mellitus as categorical covariates. The same analysis of covariance model was also used to evaluate the mean change in serum potassium from baseline to each visit during treatment, and from endof-treatment to last available follow-up visit.

For all analyses, descriptive statistics were summarized as mean and SE for continuous variables or proportions for categorical variables. Baseline demographic and clinical characteristics were summarized as mean and SD. All analyses were performed using SAS version 9.4 (SAS Institute, Cary, NC, USA), with statistical significance set at $p<0.05$.

Patiromer Efficacy without Food or with Food initial $8.4 \mathrm{~g}$ dose of patiromer (baseline/hour 0); patients were provided with a light meal after the 1-h blood draw. Starting day 2, patients began the starting dose of $8.4 \mathrm{~g}$ patiromer QD with food or without food based on their assigned treatment group.

\section{Results}

\section{Patient Disposition}

Overall, 114 patients were randomized to patiromer without food $(n=57)$ or with food $(n=57)$. Of these, 103 patients $(90 \%)$ completed the study (Fig. 2$)$; reasons for early study termination included AEs $(n=3)$ investigator's decision $(n=3)$, withdrawal by patient $(n=3)$, lost to follow-up $(n=1)$, and other reason $(n=1$; patient did not disclose taking prohibited medications). One patient in the with-food group did not receive any patiromer dose and was excluded from the efficacy and safety analyses. A second patient in the with-food group had an important protocol deviation, had no post-baseline serum potassium, and was excluded from the efficacy analyses.

\section{Baseline Demographics and Clinical Characteristics}

Of 112 patients evaluable for efficacy, the majority were men (65.2\%) and $\geq 65$ years old (65.2\%; Table 2 ). In this US study, $82.1 \%$ were white and $56.3 \%$ were Hispanic/Latino. Most of the patients had CKD (75.9\%), predominantly stages $3 \mathrm{~b}-5$ (non-dialysis) (61.6\%), hypertension (93.8\%), and diabetes mellitus (82.1\%). At 
Table 1. Patiromer titration schedule

\begin{tabular}{ll|llll}
\hline \multicolumn{1}{c}{ Day 3} & Weeks $1-3$ & & \\
\hline $\begin{array}{l}\text { Potassium } \\
\text { level }\end{array}$ & $\begin{array}{l}\geq 5.5 \mathrm{mEq} / \mathrm{L} \text { and } \\
>\text { baseline }\end{array}$ & $<3.8 \mathrm{mEq} / \mathrm{L}$ & $3.8-5.0 \mathrm{mEq} / \mathrm{L}$ & $>5.0-<5.5 \mathrm{mEq} / \mathrm{L}$ & $\geq 5.5 \mathrm{mEq} / \mathrm{L}$ \\
\hline Titration $^{1}$ & $\uparrow$ By $8.4 \mathrm{~g} /$ day & $\downarrow$ By $8.4 \mathrm{~g} /$ day & No dose change & $\uparrow$ By $8.4 \mathrm{~g} /$ day $^{2}$ & $\uparrow$ By $8.4 \mathrm{~g}^{2}$ day $^{4}$ \\
\cline { 2 - 6 } & $\begin{array}{l}\text { Proceed to next } \\
\text { weekly visit }\end{array}$ & $\begin{array}{l}\text { Proceed to next } \\
\text { weekly visit }^{3}\end{array}$ & $\begin{array}{l}\text { Proceed to next } \\
\text { weekly visit }^{3}\end{array}$ & $\begin{array}{l}\text { Proceed to next } \\
\text { weekly visit }^{3}\end{array}$ & $\begin{array}{l}\text { Proceed to next } \\
\text { weekly visit }^{3}\end{array}$ \\
\hline
\end{tabular}

${ }^{1}$ The daily dose of patiromer was increased or decreased by $8.4 \mathrm{~g}$ during the treatment period to maintain serum potassium (measured locally) within the target range of 3.8-5.0 mEq/L. At day 3 visit, patiromer dose should have been decreased to 0 for a confirmed potassium $<3.8 \mathrm{mEq} / \mathrm{L}$. If patiromer dose required titration, then initiation of the titrated dose occurred at the next planned administration.

${ }^{2}$ Dose titration was not required if the potassium decrease from the previous visit was $\geq 0.5 \mathrm{mEq} / \mathrm{L}$.

${ }^{3}$ Additional safety visits were at the discretion of the investigator; upon request, patients returned for a safety visit $<72 \mathrm{~h}$. Mandatory safety visits were required if local potassium was $>6.0 \mathrm{mEq} / \mathrm{L}$. If the dose was already $25.2 \mathrm{~g} /$ day (maximum dose) and the patient had a confirmed potassium $>6.0 \mathrm{mEq} / \mathrm{L}$, standard of care for hyperkalemia was applied at the investigator's discretion.

${ }^{4}$ If the patiromer dose was already $25.2 \mathrm{~g}$ /day and the patient had a serum potassium $\geq 5.5 \mathrm{mEq} / \mathrm{L}$, standard of care for hyperkalemia would be applied per the investigator's discretion and a safety visit may be scheduled within $72 \mathrm{~h}$, also at the investigator's discretion.

The target serum potassium range was 3.8-5.0 mEq/L, and available doses for titration were: 0 g/day patiromer (no patiromer dispensed, minimum dose), $8.4 \mathrm{~g} /$ day, $16.8 \mathrm{~g} /$ day, $25.2 \mathrm{~g} /$ day (maximum dose). For all scheduled study visits (starting from day 3 and until the last visit before the end of treatment), titration instructions were identical between the with- and without-food treatment groups.

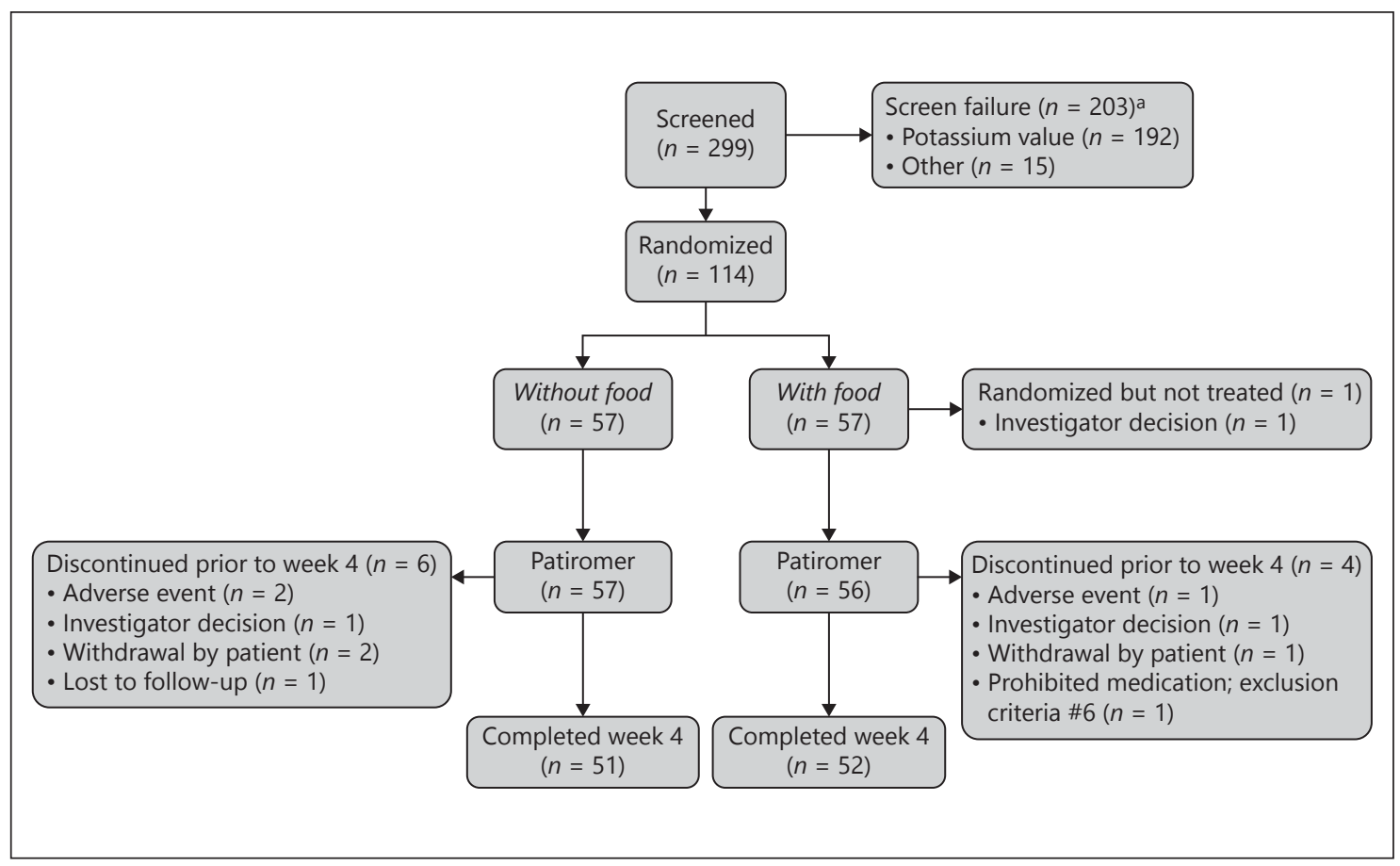

Fig. 2. CONSORT diagram. ${ }^{\text {a }}$ Screen failure: patients who met all study entry criteria except for local potassium at the screening visit could be re-screened once. More than one reason for screening failure may have been reported for a patient. Re-screened patients that had the same screen failure reason were only counted once for that reason. 
Table 2. Demographics and clinical characteristics

\begin{tabular}{|c|c|c|c|}
\hline & \multicolumn{2}{|c|}{ Patiromer treatment group } & \multirow[t]{2}{*}{$p$ value* } \\
\hline & without food $(n=57)$ & with food $(n=55)$ & \\
\hline Age, years, mean (SD) & $66.8(13.5)$ & $66.3(10.3)$ & 0.832 \\
\hline Age $\geq 65$ years, $n(\%)$ & $38(66.7)$ & $35(63.6)$ & 0.843 \\
\hline Male, $n(\%)$ & $40(70.2)$ & $33(60.0)$ & 0.322 \\
\hline \multicolumn{4}{|l|}{ Race, $n(\%)$} \\
\hline White & $48(84.2)$ & $44(80.0)$ & 0.864 \\
\hline Black & $6(10.5)$ & $8(14.5)$ & \\
\hline Other & $3(5.3)$ & $3(5.4)$ & \\
\hline \multicolumn{4}{|l|}{ Ethnicity, $n(\%)$} \\
\hline Hispanic/Latino & $33(57.9)$ & $30(54.5)$ & 0.849 \\
\hline Non-Hispanic/Latino & $24(42.1)$ & $25(45.5)$ & \\
\hline Serum $\mathrm{K}^{+}, \mathrm{mEq} / \mathrm{L},{ }^{\dagger}$ mean $(\mathrm{SD})$ & $5.4(0.4)$ & $5.3(0.4)$ & 0.166 \\
\hline$<5.5, n(\%)$ & $32(56.1)$ & $34(61.8)$ & 0.570 \\
\hline$\geq 5.5, n(\%)$ & $25(43.9)$ & $21(38.2)$ & \\
\hline CKD (all stages), $n(\%)$ & $44(77.2)$ & $41(74.5)$ & 0.827 \\
\hline CKD stages $1-3 \mathrm{a}$ & $9(15.8)$ & $7(12.7)$ & 0.785 \\
\hline CKD stages $3 b-5$ & $35(61.4)$ & $34(61.8)$ & \\
\hline Diabetes mellitus, $n(\%)$ & $48(84.2)$ & $44(80.0)$ & 0.627 \\
\hline Heart failure, $n(\%)$ & $5(8.8)$ & $5(9.1)$ & 1.000 \\
\hline Hypertension, $n(\%)$ & $55(96.5)$ & $50(90.9)$ & 0.267 \\
\hline RAAS inhibitors, $n(\%)$ & $35(61.4)$ & $31(56.4)$ & 0.701 \\
\hline Beta-blocking agents, $n(\%)$ & $28(49.1)$ & $30(54.5)$ & 0.577 \\
\hline Non-RAAS inhibitor diuretic, ${ }^{\ddagger} n(\%)$ & $18(31.6)$ & $22(40.0)$ & 0.431 \\
\hline
\end{tabular}

CKD, chronic kidney disease; $\mathrm{K}^{+}$, potassium; RAAS, renin-angiotensin aldosterone system.

* $p$ values for age and serum $\mathrm{K}^{+}$were based on 2 -sample $t$ tests and all other $p$ values were based on Fisher's exact tests.

${ }^{\dagger}$ Baseline serum $\mathrm{K}^{+}$is defined as the mean of serum $\mathrm{K}^{+}$from the central laboratory on 2 consecutive days (day -1 and day 1 ) immediately prior to the first dose of patiromer.

$\neq$ All non-RAAS inhibitor diuretics were potassium-wasting.

baseline, 66 patients (58.9\%) were receiving RAAS inhibitor therapy, including 35 (61.4\%) in the withoutfood group and 31 (56.4\%) in the with-food group. Mean (SD) serum potassium at baseline was similar in the without-food group (5.44 [0.381; 95\% CI 4.8-6.7] $\mathrm{mEq} / \mathrm{L})$ and with-food group (5.34 [0.406; 95\% CI 3.96.1] $\mathrm{mEq} / \mathrm{L})$.

\section{Efficacy}

Overall, 82.5\% (95\% CI 70.1-91.3) and 87.3\% (95\% CI 75.5-94.7) of patients in the without-food and with-food groups, respectively, achieved the primary endpoint of serum potassium in the target range $(3.8-5.0 \mathrm{mEq} / \mathrm{L})$ at either week 3 or 4 , with overlapping CIs. The least squares (LS) mean changes (SE) in serum potassium from baseline to week 4 were $-0.62(0.09) \mathrm{mEq} / \mathrm{L}$ in the withoutfood group and $-0.65(0.09) \mathrm{mEq} / \mathrm{L}$ in the with-food group (both $p<0.0001$ vs. baseline; $p=$ nonsignificant [ns] for difference between groups). In the subset with serum potassium $\geq 5.5 \mathrm{mEq} / \mathrm{L}$ at baseline, the LS mean (SE) changes in potassium from baseline to week 4 were also similar $(-0.99[0.19] \mathrm{mEq} / \mathrm{L}$ in the without-food group $[n=25]$ and $-1.11[0.16] \mathrm{mEq} / \mathrm{L}$ in the with-food group $[n=21]$; $p=n$ for difference between groups). Figure 3 shows the change in serum potassium concentrations over time for both groups. Following the discontinuation of patiromer during post-treatment follow-up, serum potassium increased toward baseline values in both groups (from a week 4 mean [SD] of 4.84 [0.517] to 5.16 [0.54] mEq/L in the without-food group, and from $4.76[0.450]$ to 5.16 $[0.53] \mathrm{mEq} / \mathrm{L}$ in the with-food group). In the prespecified subgroup analyses of the proportion of responders by serum potassium, race, eGFR, and diabetes mellitus, more than $78 \%$ of patients were responders across subgroups for each comparison, the 95\% CI overlapped between the without-food and with-food groups (Fig. 4). Comparable 
Fig. 3. Mean (SE) serum potassium over time. The shaded box represents the target range for serum $\mathrm{K}^{+}(3.8-5.0 \mathrm{mEq} / \mathrm{L})$. $\mathrm{BL}$, baseline; $\mathrm{K}^{+}$, potassium; PwoF, patiromer without food; $\mathrm{PwF}$, patiromer with food.

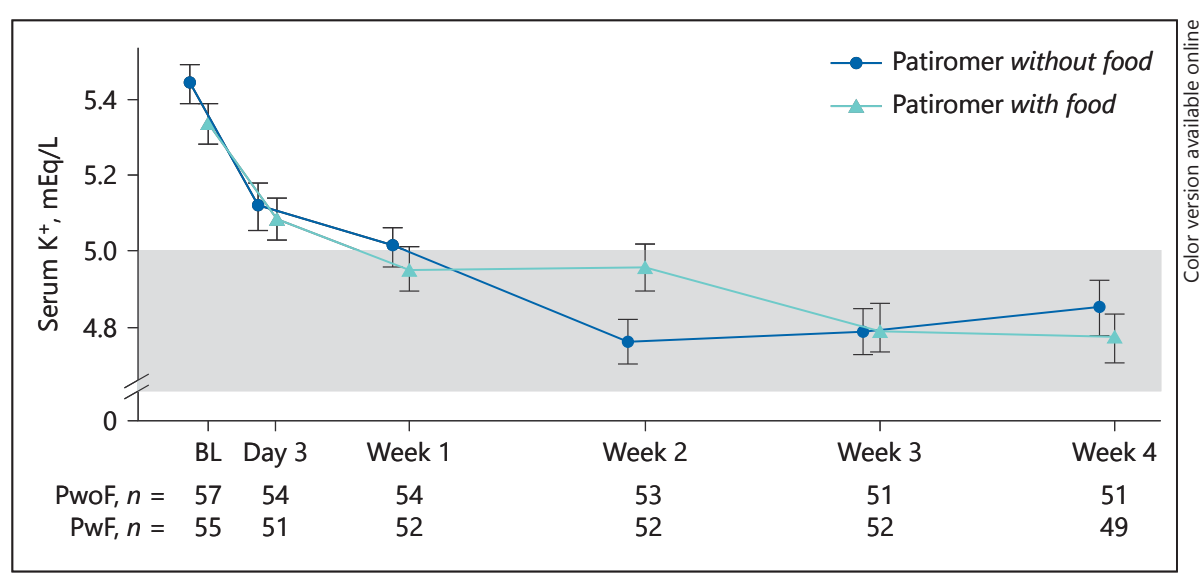

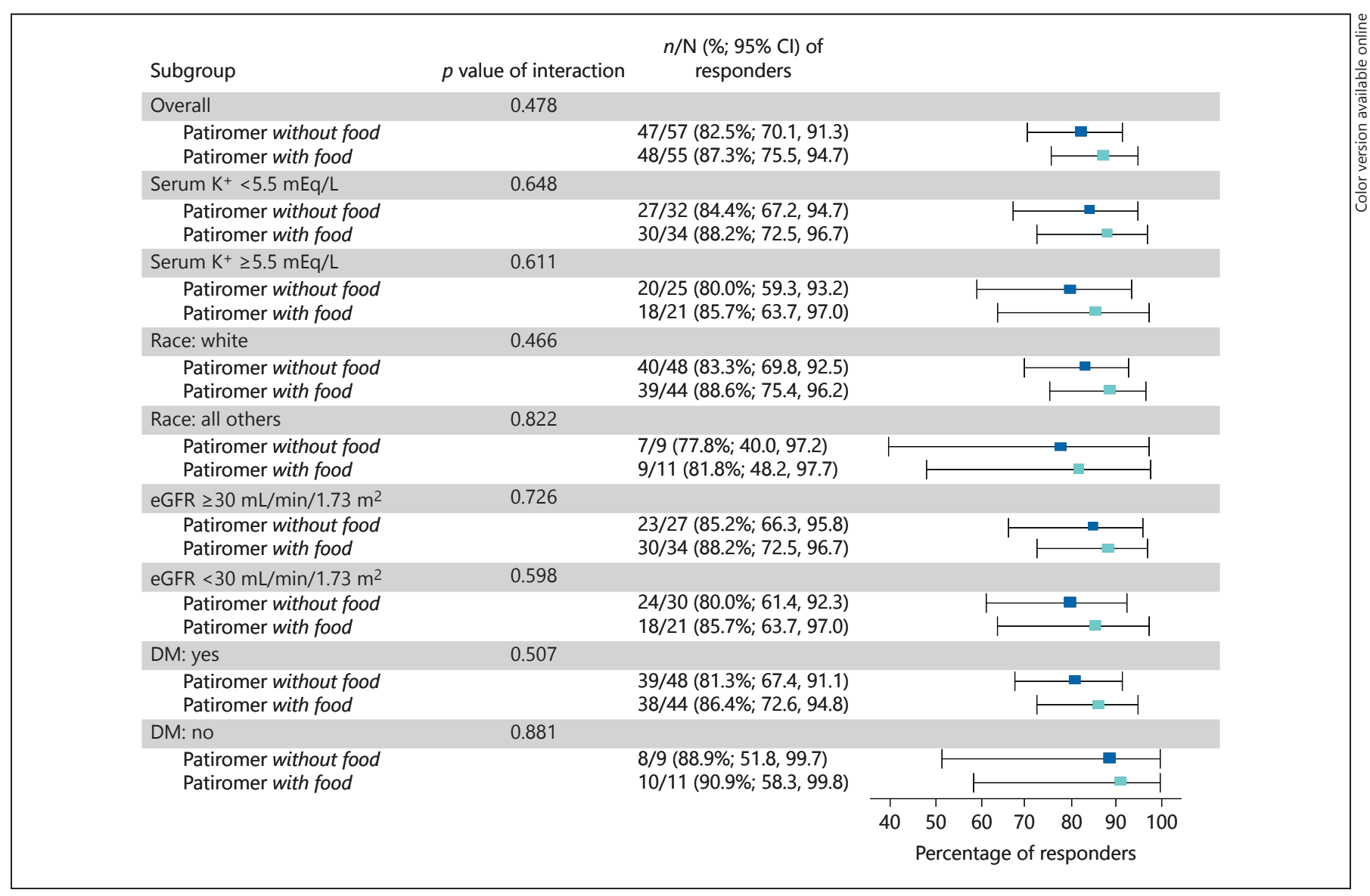

Fig. 4. Forest plot of responders at either week 3 or 4 by subgroup. DM, diabetes mellitus; eGFR, estimated glomerular filtration rate; $\mathrm{K}^{+}$, potassium. $p=\mathrm{ns}$ for all interactions between treatment groups, by chi-square test.

results were obtained in a post hoc analysis of responder rates among Hispanic/Latino and non-Hispanic/non-Latino patients. The responder rate was $87.3 \%$ (95\% CI 76.5-94.4) among the 63 Hispanic/Latino patients (81.8\% [95\% CI 64.5-93.0] in the without-food group and 93.3\%
[95\% CI 77.9-99.2] in the with-food group). Among the 49 non-Hispanic/non-Latino patients, the responder rate was $81.6 \%$ [95\% CI 68.0-91.2], and included rates of 83.3\% (95\% CI 62.6-95.3) in the without-food group and $80.0 \%$ (95\% CI 59.3-93.2) in the with-food group. 
Table 3. AEs during patiromer treatment through follow-up

\begin{tabular}{|c|c|c|c|}
\hline \multirow[t]{2}{*}{ Number of patients, $\%$} & \multicolumn{2}{|c|}{ Patiromer treatment group } & \multirow[t]{2}{*}{ Total $(n=113)$} \\
\hline & without food $(n=57)$ & with food $(n=56)$ & \\
\hline Patients with $\geq 1$ AEs & $24(42.1)$ & $27(48.2)$ & $51(45.1)$ \\
\hline \multicolumn{4}{|l|}{ Most common AEs* } \\
\hline Diarrhea & $3(5.3)$ & $3(5.4)$ & $6(5.3)$ \\
\hline Increased creatine phosphokinase & $1(1.8)$ & $3(5.4)$ & $4(3.5)$ \\
\hline Constipation & $2(3.5)$ & $2(3.6)$ & $4(3.5)$ \\
\hline Anemia & $3(5.3)$ & $0(0)$ & $3(2.7)$ \\
\hline Headache & $0(0)$ & $3(5.4)$ & $3(2.7)$ \\
\hline Urinary tract infection & $1(1.8)$ & $2(3.6)$ & $3(2.7)$ \\
\hline Patients with $\geq 1$ treatment-related AEs & $6(10.5)$ & $7(12.5)$ & $13(11.5)$ \\
\hline \multicolumn{4}{|l|}{ Most common treatment-related AEs* } \\
\hline Diarrhea & $1(1.8)$ & $2(3.6)$ & $3(2.7)$ \\
\hline Constipation & $2(3.5)$ & $1(1.8)$ & $3(2.7)$ \\
\hline Discontinuations due to AEs & $2(3.5)$ & $1(1.8)$ & $3(2.7)$ \\
\hline Patients with $\geq 1$ serious $\mathrm{AEs}^{\dagger}$ & $4(7.0)$ & $1(1.8)$ & $5(4.4)$ \\
\hline Deaths $^{\dagger}$ & $1(1.8)$ & 0 & $1(0.9)$ \\
\hline \multicolumn{4}{|l|}{ Prespecified laboratory values of interest } \\
\hline Serum $\mathrm{K}^{+}<3.5 \mathrm{mEq} / \mathrm{L}$ & $0(0)$ & $0(0)$ & $0(0)$ \\
\hline Serum $\mathrm{Mg}^{2+}<1.4 \mathrm{mg} / \mathrm{dL}^{\ddagger}$ & $3(5.4)$ & $2(3.6)$ & $5(4.5)$ \\
\hline $\begin{array}{l}\text { AEs, adverse events; } \mathrm{K}^{+} \text {, potassium; } \mathrm{N} \\
{ }^{*} \text { Occurring in } 3 \text { or more patients ove } \\
{ }^{\dagger} \text { None considered related to patirom } \\
{ }^{\ddagger} \mathrm{Mg}^{2+} \text { levels were } 1.2-1.3 \mathrm{mg} / \mathrm{dL} \text { and }\end{array}$ & $\begin{array}{l}+ \text {, magnesium. } \\
\text { in the judgment of the } \\
\text { t accompanied by syn }\end{array}$ & $\begin{array}{l}\text { vestigator. } \\
\text { oms. }\end{array}$ & \\
\hline
\end{tabular}

\section{Dosing and Titration}

The mean (SE) duration of patiromer treatment was $26.0(0.9)$ and $27.0(0.7)$ days in the without-food and with-food groups, respectively. The median (Q1, Q3) daily dose was $8.4 \mathrm{~g}(8.4,14.1)$ in the without-food group and $8.4 \mathrm{~g}(8.4,12.6)$ in the with-food group; mean (SE) number of dose titrations was similar between groups $(0.7$ [0.1] in the without-food group and 0.6 [0.1], in the withfood group).

\section{Safety/Tolerability}

Overall, 51 (45.1\%) of 113 patients evaluable for safety had at least one AE during the study (24 [42.1\%] in the without-food group and 27 [48.2\%] in the with-food group). The most common AEs (occurring in $\geq 3$ patients overall) are shown in Table 3; these included mild diarrhea in 3 patients each in the without-food and withfood groups, mild-to-moderate constipation in 2 patients in each group, and mild increased creatine phosphokinase in 1 and 3 patients in these groups respectively. AEs considered by investigators to be related to patiromer were reported in $13(11.5 \%)$ patients; the most common class of treatment-related AEs were gas- trointestinal, occurring in 7 (6.2\%) patients overall. Four patients had a total of 5 non-fatal serious AEs, none of which were deemed by investigators to be related to patiromer. These included 2 AEs of angina pectoris in one patient in the with-food group, and acute kidney injury in one patient in the without-food group; both patients were discontinued from the study. Two other patients in the without-food group had serious AEs that did not lead to interruption of patiromer dosing: intermittent claudication in one patient that resolved with treatment, and anemia in another patient that resolved without treatment. One death was reported; the patient, in the without-food group, died on study day 9 of cardiopulmonary arrest that was assessed by the investigator as not related to patiromer treatment. The patient had had type 2 diabetes mellitus, hypertension, and hypercholesterolemia and had missed the scheduled week 1 study visit due to hypoglycemia. The serum potassium measured at the last visit prior to death (day 3) was $5.1 \mathrm{mEq} / \mathrm{L}$, down from $5.4 \mathrm{mEq} / \mathrm{L}$ at baseline. The safety review board assessed the death as related to cardiovascular causes (sudden cardiac death) and unlikely to be related to hypokalemia or hyperkalemia. 
Serum potassium remained $\geq 3.5 \mathrm{mEq} / \mathrm{L}$ in all patients. One patient $(1.9 \%)$ in the without-food group experienced serum potassium $\geq 3.5$ but $<3.8 \mathrm{mEq} / \mathrm{L}$. There were no AEs of hyperkalemia (serum potassium $>5.0 \mathrm{mEq} / \mathrm{L}$ ) throughout the study.

Mean (SE) serum calcium was 9.3 (0.6) $\mathrm{mg} / \mathrm{dL}$ overall at baseline $(9.3[0.60] \mathrm{mg} / \mathrm{dL}$ in the without-food group and $9.4[0.60] \mathrm{mg} / \mathrm{dL}$ in the with-food group) and remained in the normal range $(8.5-10.5 \mathrm{mg} / \mathrm{dL})$ at all treatment visits. In both groups, mean serum calcium values were unchanged from baseline at the week 4 visit. No patient had AEs of hypocalcemia or hypercalcemia during the study.

Mean (SE) serum magnesium was $2.2(0.3) \mathrm{mg} / \mathrm{dL}$ overall at baseline $(2.1[0.4] \mathrm{mg} / \mathrm{dL}$ in the without-food group and $2.2[0.04] \mathrm{mg} / \mathrm{dL}$ in the with-food group) and remained in the normal range $(1.8-2.4 \mathrm{mg} / \mathrm{dL})$ at all treatment visits. A small mean decrease from baseline $(-0.2[0.02] \mathrm{mg} / \mathrm{dL})$ was observed with patiromer treatment, with values returning to baseline level by the end of the 2 -week post-treatment follow-up period. Prespecified abnormal laboratory values of serum magnesium $<1.4 \mathrm{mg} / \mathrm{dL}$ occurred in $5(4.5 \%)$ patients ( 3 in the without-food group and 2 in the with-food group); in 4 of these patients, serum magnesium was $<1.8$ $\mathrm{mg} / \mathrm{dL}$ (lower limit of normal) at baseline. The serum potassium measurements were $\geq 4.4$ and $\leq 5.0 \mathrm{mEq} / \mathrm{L}$ during the episodes of serum magnesium $<1.4 \mathrm{mg} / \mathrm{dL}$. In 2 patients (1.8\%; one in each treatment group) with serum magnesium $<1.4 \mathrm{mg} / \mathrm{dL}$, hypomagnesemia of moderate severity was reported as an $\mathrm{AE}$. The baseline serum magnesium levels were 1.9 and $1.6 \mathrm{mg} / \mathrm{dL}$ in these 2 patients. The lowest reported on-treatment magnesium value was $1.2 \mathrm{mg} / \mathrm{dL}$. In both cases, patiromer was continued without a dose change and the AE resolved with over-the-counter magnesium replacement. An AE of mild decreased blood magnesium was reported in $1(0.9 \%)$ patient (in the with-food group). The patient's serum magnesium was $2.1 \mathrm{mg} / \mathrm{dL}$ at baseline and the lowest on-treatment value was $1.6 \mathrm{mg} / \mathrm{dL}$ (at week 4 when the AE was reported). Patiromer treatment was completed without a dose change, and the patient completed follow-up with serum magnesium levels of $1.9 \mathrm{mg} / \mathrm{dL}$ (week 1 of follow-up) and $1.7 \mathrm{mg} / \mathrm{dL}$ (week 2 of follow-up).

There were no clinically relevant changes in vital signs or renal function laboratory parameters during the study.

\section{Discussion}

In this study, the primary endpoint (serum potassium in the range of $3.8-5.0 \mathrm{mEq} / \mathrm{L}$ at either week 3 or 4 ) was achieved by similar proportions of patients who received patiromer without and with food. Achievement of this endpoint was similar across the predefined subgroups of race, eGFR, and diabetes status. Patiromer treatment without food or with food resulted in similar reductions in the secondary endpoint of serum potassium at week 4 . In addition, the proportion of patients achieving serum potassium in the target range was similar across all patient subgroups evaluated. In general, patients with higher baseline serum potassium values had greater reductions in serum potassium than patients who started treatment with lower baseline serum potassium values, a finding consistent across all patiromer trials [18-20].

CKD and HF are highly prevalent disorders; this suggests that in an aging population, increasing numbers of patients will require treatment with RAAS inhibitors and, in turn, hyperkalemia may become an increasingly seen untoward event [21-23]. Current medical practice involves emergency treatment of acute, life-threatening hyperkalemia when observed, and often reducing RAAS inhibitor doses to prevent recurrences $[1,2]$. However, RAAS inhibitor dose reduction or discontinuation is not ideal, and more options are needed to manage mild or moderate-to-severe hyperkalemia while potentially allowing continuation of these medications at optimal doses. The demonstration that patiromer is effective at reducing serum potassium, whether given without food or with food, may ease the medication adherence burden faced by many patients with complex medical conditions who require treatment for hyperkalemia.

Patiromer was well tolerated when administered without food or with food, and the safety profile was consistent with its known safety profile [16-20]. A similar proportion of patients experienced AEs across the 2 treatment groups. Hypokalemia was not observed in this study, and only 2 patients developed hypomagnesemia, which resolved with supplementation in both cases despite continued patiromer treatment. Patients with diabetes and those treated with loop diuretics or proton pump inhibitors are at an increased risk for hypomagnesemia, and therefore, clinicians should pay special attention to magnesium levels in such individuals. The prescribing information for patiromer recommends that magnesium supplementation be considered for patients who develop low serum magnesium levels during treatment [16].

\section{Study Limitations}

This study was not designed as a true noninferiority comparison; rather, it was designed to determine if food appreciably changed the efficacy and/or safety of patiromer. Normally, food-medication interaction studies 
are small, and use pharmacokinetic comparisons based on serum drug levels. Subjects are often healthy volunteers who are generally given the study medication in both fasted and fed states to allow a generation of pharmacokinetic drug concentration-time profiles. Because patiromer is a nonabsorbed polymer, this type of formal pharmacokinetic analysis was not feasible. As such, we chose to study the therapeutic effect of patiromer on serum potassium levels when administered without food or with food to patients with hyperkalemia. The consistent findings observed in both the primary and secondary efficacy endpoints, the finding of similar efficacy across all prespecified subgroups, and the comparable safety profiles between the without-food and with-food groups suggest that neither food nor fasting affect the ability of patiromer to bind potassium within the gastrointestinal tract and lower abnormally elevated serum potassium.

In summary, patiromer is equally effective and well tolerated when taken without food or with food. These findings indicate the potential for dosing flexibility with patiromer.

\section{Acknowledgments}

Writing and editorial support services were provided by Impact Communication Partners, Inc., and funded by Relypsa, Inc., a Vifor Pharma Group Company.

\section{Disclosure Statement}

P.E.P. reports receiving honoraria from Akebia, Astra-Zeneca, Keryx, Reata, and ExThera; and reports serving as a consult or participating in advisory boards for Akebia, Vifor, and Keryx. As the principal investigator for many pharmaceutical companies, his institution has received research support. D.M.S., S.W., and J.Y. report employment by Relypsa, Inc., a Vifor Pharma Group Company. M.R.W. reports personal fees for scientific advisory boards from Relypsa and Vifor Pharma Management Ltd., both Vifor Pharma Group Companies; and from Akebia, Janssen, AstraZeneca, Sanofi, MSD, AbbVie, and Boston Scientific outside the submitted work.

\section{Grant Support}

This study was sponsored and funded by Relypsa, Inc., a Vifor Pharma Group Company.

\section{Author Contribution}

The authors made substantial contributions to the conception or design of the work (P.E.P., D.M.S., S.W., and M.R.W.), or to the acquisition, analysis, or interpretation of data for the work (all); participated in drafting and revising the manuscript; approved the final version to be published; and agreed to be accountable for all aspects of the work.

\section{References}

1 Yancy CW, Jessup M, Bozkurt B, Butler J, Casey DE Jr, Drazner MH, Fonarow GC, Geraci SA, Horwich T, Januzzi JL, Johnson MR, Kasper EK, Levy WC, Masoudi FA, McBride PE, McMurray JJ, Mitchell JE, Peterson PN, Riegel B, Sam F, Stevenson LW, Tang WH, Tsai EJ, Wilkoff BL; American College of Cardiology Foundation; American Heart Association Task Force on Practice Guidelines: 2013 ACCF/AHA guideline for the management of heart failure: a report of the American college of cardiology foundation/American heart association task force on practice guidelines. Circulation 2013;128:e240-e327.

2 National Kidney Foundation: NKF KDOQI Guidelines: K/DOQI Clinical Practice Guidelines on Hypertension and Antihypertensive Agents in Chronic Kidney Disease. New York, National Kidney Foundation, 2004. http:// www2.kidney.org/professionals/KDOQI/ guidelines_bp/guide_11.htm (accessed June 6, 2017).

3 Garg R, Yusuf S: Overview of randomized trials of angiotensin-converting enzyme inhibitors on mortality and morbidity in patients with heart failure. JAMA 1995;273:1450-1456.

Patiromer Efficacy without Food or with Food
4 Pitt B, Zannad F, Remme WJ, Cody R, Castaigne A, Perez A, Palensky J, Wittes J: The effect of spironolactone on morbidity and mortality in patients with severe heart failure. N Engl J Med 1999;341:709-717.

5 Cohn JN, Tognoni G; Valsartan Heart Failure Trial Investigators: A randomized trial of the angiotensin-receptor blocker valsartan in chronic heart failure. N Engl J Med 2001;345: 1667-1675.

6 Maschio G, Alberti D, Janin G, Locatelli F, Mann JF, Motolese M, Ponticelli C, Ritz E, Zucchelli P: Effect of the angiotensin-converting-enzyme inhibitor benazepril on the progression of chronic renal insufficiency. $\mathrm{N}$ Engl J Med 1996;334:939-945.

7 Balamuthusamy S, Srinivasan L, Verma M, Adigopula S, Jalandhara N, Hathiwala S, Smith E: Renin angiotensin system blockade and cardiovascular outcomes in patients with chronic kidney disease and proteinuria: a meta-analysis. Am Heart J 2008; 155:791-805.

8 Brenner BM, Cooper ME, de Zeeuw D, Keane WF, Mitch WE, Parving HH, Remuzzi G, Snapinn SM, Zhang Z, Shahinfar S; RENAAL Study Investigators: Effects of losartan on re- nal and cardiovascular outcomes in patients with type 2 diabetes and nephropathy. $\mathrm{N}$ Engl J Med 2001;345:861-869.

9 Epstein M, Reaven NL, Funk SE, McGaughey KJ, Oestreicher N, Knispel J: Evaluation of the treatment gap between clinical guidelines and the utilization of renin-angiotensin-aldosterone system inhibitors. Am J Manag Care 2015;21(11 suppl):S212-S220.

10 Epstein M, Alvarez PJ, Reaven NL, Funk SE, McGaughey KJ, Brenner MS, Benton W, Golestaneh L: Evaluation of clinical outcomes and costs based on prescribed dose level of renin-angiotensin-aldosterone system inhibitors. Am J Manag Care 2016;22(11 suppl):S311-S324.

11 Polson M, Lord TC, Kangethe A, Speicher L, Farnum C, Brenner M, Oestreicher N, Alvarez P: Clinical and economic impact of hyperkalemia in patients with chronic kidney disease and heart failure. J Manag Care Spec Pharm 2017;23(4-a suppl):S2-S9.

12 Epstein M: Hyperkalemia as a constraint to therapy with combination renin-angiotensin system blockade: the elephant in the room. J Clin Hypertens 2009;11:55-60. 
13 Yildirim T, Arici M, Piskinpasa S, Aybal-Kutlugun A, Yilmaz R, Altun B, Erdem Y, Turgan C: Major barriers against renin-angiotensinaldosterone system blocker use in chronic kidney disease stages $3-5$ in clinical practice: a safety concern? Ren Fail 2012;34:1095-1099.

14 Curtis LH, Mi X, Qualis LG, Check DK, Hammill BG, Hammill SC, Heidenreich PA, Masoudi FA, Setoguchi S, Hernandez AF, Fonarow GC: Transitional adherence and persistence in the use of aldosterone antagonist therapy in patients with heart failure. Am Heart J 2013;165:979-986.e1.

15 Allen LA, Fonarow GC, Liang L, Schulte PJ, Masoudi FA, Rumsfeld JS, Ho PM, Eapen ZJ, Hernandez AF, Heidenreich PA, Bhatt DL, Peterson ED, Krumholz HM; American Heart Association's Get With The Guidelines Heart Failure (GWTG-HF) Investigators: Medication initiation burden required to comply with heart failure guideline recommendations and hospital quality measures. Circulation 2015;132:1347-1353.
16 Veltassa ${ }^{\circledR}$ (patiromer): Prescribing Information. Redwood City, CA; Relypsa, Inc. November, 2016.

17 European Medicines Agency. Veltassa. http:// www.ema.europa.eu/ema/index.jsp? curl=pages $/$ medicines $/$ human $/$ medicines $/$ 004180/human_med_002141.jsp\&mid = WC0b01ac058001d124 (accessed August 4, 2017).

18 Weir MR, Bakris GL, Bushinsky DA, Mayo MR, Garza D, Stasiv Y, Wittes J, ChristSchmidt H, Berman L, Pitt B; OPAL-HK Investigators: Patiromer in patients with kidney disease and hyperkalemia receiving RAAS inhibitors. N Engl J Med 2015;372:211-221.

19 Pitt B, Bakris GL, Bushinsky DA, Garza D, Mayo MR, Stasiv Y, Christ-Schmidt H, Berman L, Weir MR: Effect of patiromer on reducing serum potassium and preventing recurrent hyperkalaemia in patients with heart failure and chronic kidney disease on RAAS inhibitors. Eur J Heart Fail 2015;17:10571065.
20 Bakris GL, Pitt B, Weir MR, Freeman MW, Mayo MR, Garza D, Stasiv Y, Zawadzki R, Berman L, Bushinsky DA; AMETHYST-DN Investigators: Effect of patiromer on serum potassium level in patients with hyperkalemia and diabetic kidney disease: The AMETHYST-DN Randomized Clinical Trial. JAMA 2015;314:151-161.

21 Murphy D, McCulloch CE, Lin F, Banerjee T, Bragg-Gresham JL, Eberhardt MS, Morgenstern H, Pavkov ME, Saran R, Powe NR, Hsu CY; Centers for Disease Control and Prevention Chronic Kidney Disease Surveillance Team: Trends in prevalence of chronic kidney disease in the United States. Ann Intern Med 2016;165:473-481.

22 Hoerger TJ, Simpson SA, Yarnoff BO, Pavkov ME, Rios Burrows NR, Saydah SH, WilliamsDE, ZhuoX:Thefutureburden ofCKD in the United States: a simulation model for the CDCCKD initiative. Am J Kidney Dis 2015;65:403-411.

23 Roger VL: Epidemiology of heart failure. Circ Res 2013;113:646-659. 